\title{
Primeiras Considerações sobre o Perfil e o Papel do Tutor no Programa Pró-Licenciatura Música d
}

\author{
Early considerations about the profile and role of the tutor in \\ the UFRGS program Pró-Licenciatura Música
}

\author{
Clarissa de Godoy Menezes
}

Helena de Souza Nunes

\begin{abstract}
The course of Licenciatura in Music - Distance Learning modality from UFRGS is the pioneer in Brazil. This course aims to improve the quality of basic education in the country through the Musical Training of Teachers that work in the area without legal clearance to do so. In the scope of this proposal, many are the professionals who contribute to the success of the proposed model. In this context, figure of the Tutor takes key role to the development of the course. The Tutor built by legal bases that regulate and conduct the program; the Tutor located historically. This work aims to interpret the action and the characteristics of this character in order to clarify the function and the profile of the Tutor in the Programa Pró-Licenciatura Música.
\end{abstract}

key words: tutor; character; profile; function.

Resumo: O curso de Licenciatura em Música - modalidade EAD da UFRGS é o pioneiro no Brasil e tem por objetivo melhorar a qualidade da educação básica no país por intermédio da Formação Musical de Professores que atuam na área sem habilitação legal para isso. Diversos são os profissionais que contribuem para o sucesso do modelo proposto, mas a figura do Tutor assume papel fundamental para o desenvolvimento do curso. Constata-se um Tutor construído a partir das bases legais que regulamentam e regem o programa; e este mesmo após os primeiros momentos de execução do projeto, isto é, um Tutor real e historicamente situado. Este trabalho tem por objetivo interpretar a ação e as características desta personagem, a fim de compreender e explicitar a Função e o Perfil do Tutor no Programa Pró-Licenciatura Música.

Palavras chave: tutor; personagem; perfil; função.

\section{Contextualização}

Em agosto de 2005, o Ministério da Educação aprova uma Resolução que estabelece a criação de cursos de Licenciatura na modalidade de educação a distância para professores das séries finais do ensino fundamental e/ ou ensino médio em exercício sem titulação, na área em que estivessem atuando. Este Programa, denominado Pró-licenciatura, tem por objetivo melhorar a qualidade da escola básica por intermédio da formação em nível superior dos professores envolvidos. 
A Universidade Federal do Rio Grande do Sul (UFRGS) em parceria com outras seis Instituições de Ensino Superior submeteu projeto para a criação do 'Curso de Licenciatura em Música - modalidade EAD', com representação e diplomação da UFRGS. Este projeto foi aprovado em terceiro lugar no país. Ao falar da formação do professor que queremos, a versão 39 do Projeto do Curso arquivada na Secretaria do CAEF da UFRGS, e posteriormente incluída na versão final, aprovada pela Câmara de Graduação e homologada pelo CEPE Conselho de Ensino Pesquisa e Extensão da referida Universidade, está explicitada a seguinte justificativa para a proposta do curso de Licenciatura em Música - modalidade educação a distância da UFRGS:

\begin{abstract}
"A proposta aqui expressa pretende contribuir de forma inovadora e, precisamente devido a isso, ainda em caráter experimental e contando com a possibilidade de correções e ajustes em andamento, para a melhoria do ensino de Música nas escolas brasileiras, concentrando-se na formação inicial de professores - Licenciatura, com vistas ao aperfeiçoando do processo educacional, inserindo-o no cotidiano da sociedade, envolvendo todos os participantes em clima alegre e descontraído, construindo com eficácia novos saberes, revigorando o desempenho geral da comunidade escolar através de experiências artístico-musicais estruturadas." (p. 03)

"a formação desejada para o professor é a de um profissional com profundo conhecimento da dinâmica da sociedade e da educação, dos sistemas de ensino e da escola enquanto realidades concretas de um contexto histórico-social, nas dimensões afetiva e ética, individual e grupal, um profissional efetivamente comprometido com a dimensão pública da educação, capaz de enfrentar problemas referentes à prática educativa em suas diferentes modalidades; que use o conhecimento musical para gerar e difundir novas tecnologias e inovar o trabalho educativo na escola e em outros espaços organizacionais e comunidades educativas; que investigue e produza conhecimento sobre a natureza e as finalidades da Música, em cada determinada sociedade, bem como sobre os meios apropriados de formação humana pela formação dos quais é ele responsável.” (p.18)
\end{abstract}

A figura do Tutor, no contexto educacional do Programa Pró-Licenciaturas, é de fundamental importância para o desenvolvimento da proposta (MEC, 2007). É ele que terá contato direto praticamente diário com os professores-alunos, fazendo a intermediação entre a realidade acadêmica e o chão da escola. O curso terá 14 pólos espalhados por todo o território nacional, e deverá contar com uma estrutura operacional acadêmica e de apoio tanto nos pólos quanto na universidade. O modelo do curso da UFRGS atuará em conjunto com a Rede Nacional de Formação Continuada de Professores da Educação Básica, de maneira integrada, a fim de otimizar recursos e esforços, por intermédio do Centro de Artes e Educação Física da UFRGS (CAEF da UFRGS).

Os tutores que irão atuar no Curso de Licenciatura em Música - modalidade EAD da UFRGS foram selecionados de duas maneiras. Em um primeiro momento, foi aberto um Edital de Processo Seletivo para Tutores. Ao efetivo início do curso, quase dois anos após o referido processo, houve desistência de tutores selecionados. Sem tempo nem recursos previstos no Plano de Trabalho Anual (PTA) para novo processo seletivo, foram realizados contatos diretos com pessoas, cujo perfil poderia se enquadrar nas funções de tutoria do curso, a fim de completar o quadro de tutores.

Aqueles que foram selecionados pelo processo seletivo original, atuaram desde o ano de 2006, contribuindo para a confecção dos materiais didáticos, em parceria com o CAEF da UFRGS. Aqueles que foram selecionados posteriormente entraram em contato com a proposta durante a etapa presencial de formação de tutores, realizada em fevereiro de 2008. Durante esta etapa, foi percebida uma grande dificuldade, por parte de todos eles, em entender qual era o seu papel na proposta. Mesmo aqueles que já atuavam junto ao CAEF há mais tempo, revelaram desconhecer a real dimensão de suas ações no decorrer da implementação do curso. 


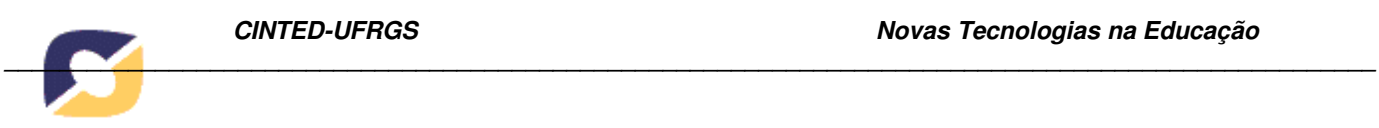

\section{Objetivo e Justificativa}

Fortemente motivado e justificado por esta constatação, este trabalho tem por objetivo esclarecer, com base em uma perspectiva histórico-hermenêutica, o Perfil e a Função do Tutor no curso de Licenciatura em Música - modalidade educação a distância da UFRGS.

A metáfora usada para que os tutores presentes no Curso de Capacitação de Tutores pudessem compreender seu papel na proposta foi a do ator/ personagem. O ator é aquele que age; a personagem é um papel interpretado por um ator. Sobre este aspecto, Mallet (2000) é categórico "você não pode ser a personagem. Por definição - você é você. Segundo, você não pode sentir as coisas que a personagem sente." Sendo assim, quando usarmos neste trabalho o termo Função a definiremos como: o conjunto de ações as quais o ator realiza para interpretar a personagem. E o Perfil é o conjunto de características necessárias à pessoa deste ator, para que ele desenvolva esta personagem, sob domínio da vontade e da inteligência. A nossa personagem é o Tutor e nossos atores são selecionados para atuarem neste papel. O tutor é, portanto e talvez antes de tudo, um artista.

Segundo Mallet (2000) a "formação do artista é também a construção de um olhar, de uma maneira de olhar, um olhar que pretenda compreender." Na proposta pedagógica do projeto do curso de Música da UFRGS, essa compreensão passa pelo entendimento das bases legais que regulamentam e regem o Programa de Formação Inicial para Professores em Exercício no Ensino Fundamental e no Ensino Médio (Pró-Licenciatura), e o conhecimento do estudo pregresso da função e perfil do tutor através dos tempos, na busca de entender o contexto em que os tutores do Programa Pró-licenciaturas Música estão inseridos. Isto porque, à medida que as personagens estiverem compreendidas, qualquer ator poderá interpretá-la; com maior ou menor grau de beleza, o que, por sua vez, dependerá de sua vocação, sua formação e seu empenho. Mas isso já será outra história!

\section{Fundamentação e bases teóricas}

A base legal deste trabalho está constituída pelos documentos oficiais que dão origem e continuidade ao Programa Pró-licenciatura do MEC. Sendo assim, analisaremos: a Resolução FNDE/CD/N³4, de 9 de Agosto de 2005 e seus anexos; a Resolução/FNDE/CD/ nº 49, de 29 de dezembro de 2006; o Edital de Seleção de Tutores do Curso de Licenciatura em Música Modalidade à Distância da UFRGS; e o Relatório do Plano de Trabalho de 2006 do curso de Música, no âmbito do Pró-Licenciaturas Fase II.

\subsection{Resolução/CD/FNDE/N ${ }^{\mathbf{0}} 34$, de 9 de Agosto de 2005}

A Resolução/CD/FNDE/N 34 , de 9 de Agosto de 2005 origina o Programa Pró-Licenciaturas Música e fixa parâmetros para a discussão do Perfil e Função do Tutor em discussão.

Neste documento, não encontramos referência específica ao perfil ou a função do tutor no Programa; no entanto, a Resolução estabelece que a atribuição de produzir e enviar relatório de avaliação de desempenho de tutores será de responsabilidade da Instituição de Ensino Superior (IES) a qual o Programa estiver vinculado. O documento também estabelece que a periodicidade deste relatório será semestral, e deverá ser encaminhado à SEB e à SEED. Entretanto, não é divulgado o meio - se digital e/ou material impresso - que deverá ser utilizado para o envio desta documentação. Constam na Resolução/CD/FNDE/N $34 / 2005$ 
quatro Anexos, todos estudados para a realização deste artigo. Todavia, apenas os Anexos II e III da referida Resolução demonstram maior relevância de análise para o âmbito deste estudo. O Anexo II, por se referir às especificações técnicas do projeto de curso, e o Anexo III, por contemplar as propostas conceituais e metodológicas do Programa Pró-Licenciatura do MEC.

\subsubsection{Anexo II: Especificações Técnicas do Projeto de Curso}

O Anexo II da Resolução/CD/FNDE/N $34 / 2005$ estabelece que as Instituições de Ensino Superior (IES), ao elaborarem suas propostas de curso a ser ofertado, devem estar em consonância com o Anexo III da referida Resolução e respeitar a forma e condições estabelecidas na Resolução. Dentre os itens obrigatórios, nos cabe aqui ressaltar os de número 5 e 6 . O item obrigatório número 5 baliza a descrição das equipes multidisciplinares, a saber: 1. O tutor é parte integrante da equipe acadêmica responsável pelo curso (subitem 5.2); 2. É da IES proponente do curso a responsabilidade de definir a concepção de tutoria e tutor, incluindo tutoria presencial e a distância (subitem 5.3); 3. Deve constar no Projeto de Curso o detalhamento dos requisitos para ocupação das funções de tutor (subitem 5.4). O item obrigatório seguinte, de número 6 , aborda as questões relativas ao projeto pedagógico do curso. $\mathrm{O}$ item está dividido em três subitens assim apresentados: fundamentação e objetivos, organização curricular e proposta metodológica. Embora muito influencie na definição do perfil e da função do tutor no curso, não há citações diretas ao tema.

A análise destes dois itens do Anexo II nos leva a constatar que o governo transfere para a IES proponente do curso o dever de instituir o perfil e as funções dos tutores. Conforme consta no próprio documento, esta medida se faz necessária para que sejam respeitadas as especificidades de cada curso, garantindo maior autonomia na construção das bases pedagógicas do curso proposto, assim como aumentando a probabilidade de consonância entre o perfil do tutor e do profissional que se pretende formar.

\subsubsection{Anexo III da Resolução/CD/FNDE/N³4/2005: Propostas Conceituais e Metodológicas}

O Anexo III da Resolução/CD/FNDE/N $34 / 2005$ é o mais extenso e complexo dos quatro documentos estudados. Este anexo foi publicado separadamente e, segundo o MEC (2005), "é o documento que contém as Propostas Conceituais e Metodológicas do Programa PróLicenciatura." (BRASIL, 2005, Anexos 1 a 4, p. 5, grifo do autor).

Por intermédio deste documento fica explicitado o objetivo do Programa, qual seja: a "melhoria da qualidade do ensino na Educação Básica" (BRASIL, 2005, Anexo III, p.3). Conforme MEC (2005) "qualquer iniciativa que vise melhorar a qualidade do ensino deve eleger a escola como agente transformador" (BRASIL, 2005, Anexo III, p.6). Para tanto, o MEC deixa explícito em seu discurso que o professor tem papel fundamental nesta ação transformadora:

"O professor que queremos é um profissional capaz de contribuir para a construção dessa escola, preparado para propor e implementar as ações necessárias à sua transformação." (BRASIL, 2005, Anexo III, p. 8)

É neste anexo que encontramos um maior número de referências diretas à figura do tutor. No que se refere ao perfil e função, nos interessa aqui analisar os subitens 3.4, que estabelece as 


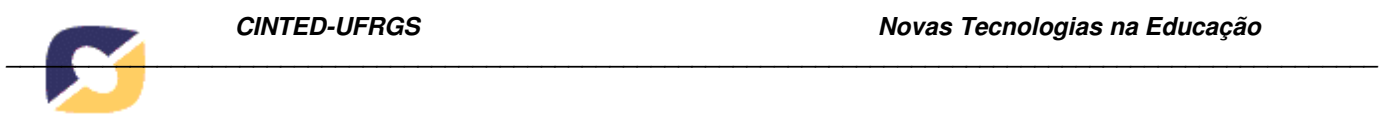

diretrizes norteadoras metodológicas e pedagógicas do Pró-Licenciatura; e 3.5, relativo à operacionalização do Programa. No item 3.4, destacamos a diretriz de número 3:

"a experiência dos professores deve ser ponto de partida para a reflexão sobre a prática pedagógica. Para tal, será estimulada a presença do tutor na escola em que o professor atua, planejando e refletindo sobre a ação do professor e como ela pode ser transformada;" (BRASIL, 2005, Anexo III, p. 10, grifo do autor)

Ao analisar esta diretriz, pode-se elencar como função do tutor: a) estar presente na escola; b) planejar e refletir sobre a ação do professor; e c) propor transformações a partir das observações feitas. Com base neste conjunto de idéias, entendemos que seriam características adequadas ao perfil de tutor: a) pró-ativo; b) solidário; c) sensível; e d) capaz de dialogar com a realidade e com os fatos do cotidiano escolar.

Mais adiante no documento, no item 3.5 que trata da operacionalização do Programa, encontramos função e perfil semelhante ao destacado no parágrafo anterior. A diretriz de número 13 (BRASIL, 2005, Anexo III, p. 14) define como função do tutor: a) visitar o local de trabalho do professor-aluno; e b) discutir [estabelecer uma ponte entre] a prática profissional do professor e o que está sendo estudado no curso. Este tutor tem portanto, por principal característica ser o mediador da ação pedagógica, na relação formação - atuação profissional.

Outra função expressa no item de operacionalização do Programa é a de [integrar e] interagir com os professores-alunos e os demais tutores. Conforme consta na diretriz de número 17: "será disponibilizado ambiente virtual de aprendizagem para promover a interação não só entre os professores-alunos como entre esses e os tutores e entre os próprios tutores." (BRASIL, 2005, Anexo III, p. 14) Podemos deduzir que este tutor deverá ter como perfil conhecimento em: a) Informática na Educação; b) Novas tecnologias de educação; c) Educação a Distância; além de ser capaz de socializar-se por intermédio de meios eletrônicos.

O governo também estabelece como importante garantir a formação inicial e continuada deste tutor no âmbito do curso. Isto fica claro nas diretrizes de número 5, 16 e 22 do Anexo III. Ao caracterizar como dever da IES selecionada do curso "propor processo de formação de tutores" (BRASIL, 2005, Anexo III, p. 13), o MEC sinaliza que é também função do tutor qualificar seus conhecimentos. Apontando, desta maneira, o perfil de pessoa, permanentemente receptiva a novas aprendizagens.

A diretriz 16 determina que "os tutores terão acesso a todo material fornecido ao aluno, além de um guia do tutor em meio impresso" (MEC, 2005, Anexo III, p. 14). Podemos depreender desta diretriz que, com relação ao material do curso, é função do tutor: a) conhecer; b)estudar; e c) acompanhar a implementação deste junto ao professor-aluno. Portanto, o perfil necessário para que se cumpram estes quesitos seria o de tutor pesquisador, observador.

Por último, destacamos o que diz a diretriz de número 22 "na medida do possível, os tutores dos pólos devem ser professores da rede pública local com, no mínimo, formação superior (licenciatura); ideal com pós-graduação em educação ou área afim. Atuarão sob orientação da IES responsável pela implementação na região. Estes tutores deverão participar de programa de formação especialmente desenvolvido para este fim;" (BRASIL, 2005, Anexo III, p. 15) Esta diretriz estabelece como função do tutor: a) seguir orientação da IES responsável b) participar de programa de formação no âmbito do curso. c) preferencialmente ser professor da rede pública, com formação superior (licenciatura), ideal pós-graduação em educação ou área afim. 


\section{2 Resolução/FNDE/CD/ n 49, de 29 dezembro de 2006 - Diretrizes para concessão de bolsas de estudos pelo Pró-Licenciatura}

A Resolução no 49, de 29 de dezembro de 2006 "Estabelece orientações e diretrizes para a concessão de bolsas de estudo e de pesquisa para participantes do Pró-Licenciatura, no âmbito do Ministério da Educação" (MEC/FNDE, 2006, p. 1).

No caput do artigo terceiro da Resolução a expressão funções é usada para definir os personagens, as ações, e o perfil dos profissionais envolvidos no Programa e que poderão receber bolsa. Nos interessa aqui analisar os artigos terceiro e quinto desta Resolução. A alínea c) do artigo terceiro define como tutores os "participantes do curso no exercício de tutoria voltada à aprendizagem dos professores da educação básica matriculados nos cursos de formação inicial" (FNDE, 2006, p. 2). Mais adiante nesta mesma alínea, é exigido como formação mínima deste tutor

"nível superior e experiência de 1 (um) ano no magistério. Admite-se a seleção de tutores com formação mínima em nível médio e experiência de 1 (um) ano no magistério nas regiões de execução do curso onde houver carência de tutores com formação em nível superior" (ibid, p. 2)

Já no artigo quinto, que versa sobre as obrigações dos participantes, nos interessa destacar a alínea f) do inciso três, que delega às IES que ofertarem o curso de licenciatura EAD a atribuição de "proceder à seleção dos professores pesquisadores, formadores e tutores de curso, de acordo com os critérios definidos nas diretrizes do Programa" (FNDE, 2006, p. 3).

\section{3 Edital do Processo Seletivo para Tutores do Curso de Licenciatura em Música - Modalidade à Distância}

O Edital do Processo Seletivo para Tutores do Curso de Licenciatura em Música Modalidade à Distância identifica dois profissionais com Função e Perfil diferenciados para o trabalho de Tutor: os tutores no pólo e os tutores na universidade. Sua função comum é a de facilitar e acompanhar o acesso dos estudantes aos enfoques temáticos e às atividades relacionadas ao curso de Licenciatura em Música.

Segundo o Projeto Pedagógico, o tutor no pólo têm por função "agir como mediador no processo de aprendizagem de um grupo de 60 cursistas, promovendo interações entre participantes e, na medida do possível, resolvendo dúvidas de conhecimento específico. Também caberá a esse tutor a mediação das avaliações e a responsabilidade pelo acompanhamento e registro das avaliações presenciais." A função geral deste Tutor é "proporcionar motivação, feedback, diálogo, orientação personalizada e orientação coletiva em atividades presenciais e coletivas, bem como estabelecer vínculos com cada cursista, incentivando-o e encorajando-o em seu próprio processo de estudo."

Já os tutores sediados na universidade terão por função a) atender os diversos módulos de conteúdos em funcionamento; b) trabalhar diretamente sob a supervisão do coordenador do corpo docente; e c) estar operacionalmente vinculado aos professores formadores. Conforme o edital, sua função é "facilitar e acompanhar o acesso dos estudantes aos enfoques temáticos e às atividades relacionadas." No que se refere ao perfil deste profissional, "o tutor na universidade deverá ter formação específica nas interdisciplinas (área) que atende." Seu atendimento será predominantemente on-line. Neste Edital, a experiência em docência especialmente na modalidade EAD - também é considerada uma característica importante do 
Perfil destes tutores. Outro aspecto importante a ser ressaltado é a preocupação com a garantia de formação inicial e continuada destes tutores, bem como sua adequação ao modelo pedagógico do curso, evidenciada no item que refere a avaliação adicional ao Processo Seletivo.

\subsection{Relatório do Plano de Trabalho de 2006}

$\mathrm{Na}$ Apresentação do Relatório do Plano de Trabalho de 2006, se lê que ele "atende especificações do Of. Nº62/2008-DPEAD/SEED/MEC, de 08 de janeiro de 2008, para a elaboração do Relatório sobre execução dos recursos descentralizados a UFRGS, no exercício de 2006, para oferta do curso de Música, no âmbito do Pró-Licenciaturas Fase II." (sem número de página)

No item referente às metas cumpridas, a ação Formação de Tutores aponta a função dos Tutores durante aquele ano. Os tutores desempenharam tarefas como: a) desenvolver materiais didáticos, sob orientação de alguns dos professores pesquisadores; b) participar de diversas iniciativas de formação continuada de professores da Educação Básica desenvolvidos pelo CAEF da UFRGS. As atividades desempenhadas pelos tutores no ano de 2006 demonstram consonância entre a proposta do curso e a resolução e seus anexos.

\section{O Tutor através dos tempos - definição do termo e revisão bibliográfica}

Segundo Harper (2001) o termo Tutor é encontrado pela primeira vez em 1377 e deriva do francês antigo, tutour; sua função seria de guardião, aquele que tem custódia sobre. O termo também é encontrado no decorrer da história como guardião, professor particular, aquele que cuida, estudante senior designado para ajudar nos estudos do estudante junior. Sua origem estaria no latim e em outras línguas não identificadas (HARPER, 2001, tradução nossa).

Ferreira (1986), por sua vez, situa a palavra Tutor como derivada do latim, tutore, que significa "1. Indivíduo legalmente encarregado de tutelar alguém. 2. Protetor, defensor [...] 4. Aluno designado como professor de outros alunos, em formas alternativas de ensino" (FERREIRA, 1986, p. 1729). Houaiss (2001) afirma que a palavra tutor tem sua origem no século XIII e possui diferentes significados de acordo com a área que está sendo empregada. Durante a revisão bibliográfica, buscou-se também a opinião de autores como Bellodi (2003), Correia (2007), Emerenciano et. al (meio digital), Ferreira et. al (2005), Wikipedia (meio digital) que corroboram as definições apresentadas.

Conforme Marky (1992), no Direito Romano o Tutor tinha por função administrar o patrimônio do pupilo sob sua tutela; caso não cumprisse com suas obrigações de maneira adequada, poderia ser denunciado por qualquer cidadão, sendo afastado do cargo. Se condenado no processo, este tutor sofreria a pena de infamia. Dependendo da idade do pupilo, o Tutor poderia administrar diretamente os bens do infante ou apenas acompanhar e autorizar as decisões daquele.

Bellodi (2003) discute o papel do tutor (mentor) em um grupo de professores de Medicina o definindo como a "figura de suporte para o caminhar pessoal e profissional do aluno"; tendo por função orientar, aconselhar, acompanhar a trajetória do aluno, servir de referência, compartilhar experiências, encorajar e refletir com o alunos (Bellodi, 2003, p. 207 e 210). 
Historicamente, podemos observar uma mudança de paradigmas na função do Tutor EAD impulsionada pela inclusão de novas tecnologias em educação mediadas pelo uso da internet. Conforme Ferreira et. al (2005)

"por volta da década de 60, a EAD utilizava material impresso e/ou mídias de massa (basicamente o rádio e a televisão) e desta forma o tutor tinha como tarefa assegurar o cumprimento dos objetivos do curso cuidando para que os alunos recebessem os materiais necessários à sua autoaprendizagem." (FERREIRA et al., 2005, p. 2 -3)

Em estudo que aborda o trabalho de uma equipe de tutores em uma escola privada que oferece cursos a distância, Sarmet e Abrahão (2007) concluem que o "papel do tutor é mediar a interação entre os instrutores, os alunos e as Escolas Licenciadas, bem como atender às diferentes demandas dos alunos" (SARMET; ABRAHÃO, 2007, sem número de página). Neste mesmo estudo, os autores transferem a função de tutoria para o professor a distância; conforme Belloni (apud SARMET; ABRAHÃO, 2007, sem número de página) "O docente na $\mathrm{EaD}$ passa a ter funções de criador, formador e realizador de cursos e materiais, pesquisador, tutor, "tecnólogo educacional" e monitor."

Na opinião de Maggio (apud FERREIRA et al., 2005, p. 3) o tutor EAD tem por função: a) criar propostas de atividades para a reflexão; b) apoiar sua resolução c) sugerir fontes de informação alternativas; d) oferecer explicações; e e) facilitar os processos de compreensão; isto é, guia, orienta, apóia. Ao ressignificar a função do Tutor EAD Emerenciano et. al (meio digital) o situa como professor e educador. Fortalecendo esta perspectiva Barros (meio digital) afirma que o "Tutor é um educador a distância” (LEAL, meio digital, p.3).

\section{O Tutor no curso de licenciatura em música modalidade EAD da UFRGS}

O Curso de Licenciatura em Música da UFRGS - modalidade EAD está estruturado sob uma Equipe Acadêmica, constituída por componentes de caráter pedagógico e de apoio. A Equipe Pedagógica é formada por um coordenador geral, um coordenador de material didático, um coordenador de corpo docente, 28 tutores, e 35 professores autores/formadores. A Equipe de Apoio é formada por um coordenador financeiro, um técnico de redes, um webdesigner, um programador, um secretário, e 14 músicos especializados em mídias digitais. Estas duas Equipes atuam no pólo e na Universidade. As funções exercidas pelos profissionais que atuam na Equipe Pedagógica se organizam em três dimensões: Pedagógica, Social e Organizativa (Projeto de Curso, p. 11).

Originalmente, os tutores dividiam-se em Tutor no Pólo e Tutor na Universidade. No entanto, após a seleção dos tutores e o aprofundamento do pensamento operacional do projeto, se constatou mais producente a divisão dos tutores em Tutores Locais Residentes e Itinerantes; e Tutores na Universidade. A nomenclatura Tutor no Pólo é encontrada no Projeto de Curso, que foi o documento elaborado na ocasião da seleção das IES para o oferecimento dos cursos de Licenciatura modalidade EAD. Já os termos Tutor Local Residente e Itinerante aparecem no Manual do Aluno e foam largamente utilizados ao longo da semana presencial do Curso de Capacitação de Tutores. Sendo esta uma nomenclatura desenvolvida no decorrer da trajetória de implementação do curso, e tendo influência na função exercida pelo Tutor, a análise será feita respeitando o decurso histórico. Sendo assim, primeiro analisaremos a figura Tutor no Pólo e após, suas funções como Tutores Locais Residentes e Itinerantes. 


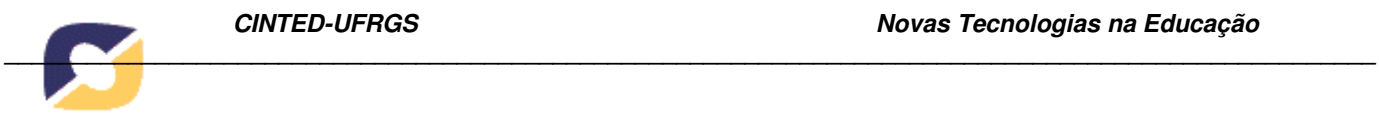

Conforme consta no Projeto de Curso, o tutor no pólo tem por função a) orientar presencialmente os cursistas do pólo; b) interagir à distância com os professores formadores e tutores na universidade; c) agir como mediador no processo de aprendizagem; d) promover interações entre professores-alunos; e) resolver dúvidas de conhecimento específico, na medida do possível; f) mediar as avaliações; e h) acompanhar e registrar as avaliações presenciais. (p. 14) Segundo o Projeto de Curso, a função geral do tutor é "proporcionar motivação, feedback, diálogo, orientação personalizada e orientação coletiva em atividades presenciais e coletivas, bem como estabelecer vínculos com cada cursista, incentivando-o e encorajando-o em seu próprio processo de estudo." (p.14)

A dimensão Pedagógica de sua função está relacionada à inclusão do professor-aluno no curso em todos os aspectos educacionais necessários à compreensão da Proposta Metodológica contida no curso. Para isso, o tutor local ou no pólo deverá ajudar o cursista a planejar e organizar seu envolvimento e desenvolvimento no curso, por intermédio de acompanhamento sistemático das atividades realizadas por cada estudante nas interdisciplinas, além de suas interações com os outros colegas.

A dimensão Social desta função está relacionada à postura com que este tutor irá desenvolver as tarefas pedagógicas, devendo criar ambiente acolhedor para a aprendizagem dos alunos e condições para que estes se desenvolvam e participem individual e coletivamente das atividades do curso. O Tutor deve estar atento ao ambiente virtual de aprendizagem, evitando abandono de curso por parte dos professores-alunos. Também tem por responsabilidade social orientar e incentivar discussões de ideais e comportamentos éticos.

A dimensão Organizativa da função do Tutor se estabelece nos procedimentos administrativos da dimensão pedagógica. O Tutor deve acompanhar o cursista e orientá-lo em sua própria organização. Também é de responsabilidade desta dimensão o relato da trajetória de cada professor-aluno para os tutores na Universidade e para os professores formadores. Ou seja, é por intermédio desta dimensão que a Equipe na Universidade se manterá informada das questões pedagógicas que envolvem cada professor-aluno.

Redigida posteriormente, a função do Tutor que deverá atender os alunos presencialmente no pólo, encontrada no Manual do Aluno, se divide em duas categorias: Tutor Local Residente e Tutor Local Itinerante. A função do Tutor Local Residente é a que mais se aproxima do que no Projeto de Curso se denominou Tutor de Pólo. Ele é que atenderá presencialmente o cursista, tendo sob sua responsabilidade a função de a) garantir o sucesso na realização das atividades pertinentes a cada interdisciplina; b) interagir à distância com os professores formadores e tutores na universidade; c) mediador o processo de aprendizagem do grupo local; d) promover interações entre participantes, encorajamento e, na medida do possível, resolver dúvidas de conhecimento específico; e f) acompanhar e registrar as avaliações presenciais. (Nunes, 2007, p. 23)

O Tutor Local Itinerante é uma categoria de tutoria intermediária entre o atendimento presencial e o atendimento à distância, surgida da impossibilidade de se conseguir tutores com formação musical em número suficiente para cada localidade. Este tutor fará o acompanhamento do desenvolvimento musical do aluno, sendo responsável por estar presencialmente em dois ou mais pólos, com freqüência definida de acordo com a necessidade da demanda. É função deste tutor "realizar a orientação musical mediada pela internet, em 
particular na utilização dos e-books de violão e teclado e dos diversos sites de interdisciplina, junto aos estudantes e aos próprios tutores residentes." (Nunes, 2007, p.23/ 24). Sendo assim, enquanto para o tutor residente é mais importante o olhar humano, social e organizativo, o tutor itinerante deve se concentrar mais na qualidade de conteúdos e ter um olhar predominantemente didático-pedagógico, o que o faz adquirir uma qualidade que poderíamos denominar de personagem-interface.

Isso porque a redefinição da função do Tutor de Pólo para Tutor Local Residente e Itinerante, por sua vez, acarretou também uma mudança na função do Tutor na Universidade. Segundo o Projeto de Curso, o Tutor na Universidade é o "responsável pelo assessoramento em conteúdos específicos aos pólos, que em princípio atuará sediado na UFRGS, mas que também poderá atuar presencialmente de forma itinerante junto aos Pólos, se necessário." (p.15). A inclusão da categoria de Tutor Local Itinerante nos remete a duas hipóteses, as quais poderiam comprometer a consistência interna do modelo. Primeiro, que a expectativa de o tutor na Universidade atuar itinerantemente de forma presencial no Pólo, aparentemente, deixa de existir; segundo, que poderá haver uma sobreposição de funções entre estes dois tutores, podendo, então, confundirem-se tarefas sob responsabilidade de um e outro.

Mas é precisamente aqui que a compreensão do Tutor sob a ótica da relação ator-personagem de Mallet se torna esclarecedora, pois os atores (profissionais selecionados) atuarão como e quando estiver determinado no script de uma peça que requer improvisação e inclui interferências do público, desempenhando este ou aquele papel, na condição de personagem. Os papéis existentes e, portanto, as personagens possíveis são: Tutor na Universidade e Tutores no Pólo, com desempenho residencial e/ou itinerante. Que ator os desempenhará e com que qualidade de interpretação vai depender do momento da encenação e estará de acordo com a competência e a versatilidade de cada ator. Sem confundir-se com sua atuação enquanto personagem, as condições pessoais do artista, no que se refere à competências e versatilidade, serão determinantes tanto para suas escolhas pessoais por papéis como para o cumprimento das atribuições esperadas dele pela coordenação do curso.

\section{Conclusão}

A Legislação que rege os cursos do Programa Pró-Licenciatura estabelece normas referentes ao Tutor, em cursos para formação de professores à distância, que possuem caráter essencial, porém meramente balizador. Verifica-se um claro encaminhamento das definições finais sobre o perfil e a função deste profissional às Instituições de Ensino Superior. Os projetos sob responsabilidade destas Universidades, por sua vez, sofrem adaptações ao longo de seu efetivo desenvolvimento.

Isso acontece também com o Curso de Licenciatura em Música - modalidade EAD da UFRGS, cuja previsão da necessidade de correções e ajustes ao modelo proposto é encontrada já em sua justificativa, tendo em vista seu caráter experimental e inovador. Neste contexto altamente dinâmico, destaca-se a figura do Tutor, que, mesmo proposto a partir das bases legais que regulamentam e regem o programa, após os primeiros momentos de execução do projeto, revela características surpreendentes. Trata-se do Tutor real e historicamente situado.

Esse, por sua vez, pareceu correr riscos de inconsistência, no Programa Pró-Licenciatura Música. Atenta ao fato, a coordenação buscou explicitá-lo, encontrando na relação ator- 
personagem de Mallet uma base teórica consistente. Pelo menos para o lançamento de uma proposição de debate. A idéia de construção da personagem com base na versatilidade $e$ competências do ator, no contexto de uma peça que inclui interferência do público e técnicas de improvisação pode explicitar assim o fenômeno dinâmico e imbricado que se observa nas tarefas próprias aos desempenhos residenciais e/ou itinerantes dos tutores. A partir disso, definições encontradas no modelo proposto podem ser revisadas e compreendidas, garantindo a boa qualidade da performance, no caso, do curso.

Em resumo, interpreta-se e fundamenta-se o funcionamento das tutorias em um curso de Música, sob a ótica do Teatro. Esse olhar possibilita uma orquestração afinada, harmonizado a Lei, o cotidiano e seu próprio ambiente, qual seja, a Arte.

\section{Referências Bibliográficas}

BELLODI, Patrícia Lacerda. O que É um Tutor? Representações do Papel em um Grupo de Professores de Medicina durante o Processo de Seleção Revista Brasileira de Educação Médica Rio de Janeiro, v.27, $\mathrm{n}^{\circ}$ 3, set./dez. 2003 Disponível em: <http://www.abemeducmed.org.br/rbem/pdf/volume_27_3/o_que_e_tutor.pdf> Acesso em: mar. 2008.

BRASIL. Resolução/CD/FNDE/N 34 , de 9 de Agosto de 2005 Disponível em: $<$ http://www.fnde.gov.br/home/index.jsp?arquivo=legislacao.html\#prolicenciatura $>$ Acesso em: mar. 2008.

BRASIL. Anexo II da Resolução/CD/FNDE/N $\mathbf{N}^{\mathbf{3} 4 / 2005}$ Disponível em: $<$ http://www.fnde.gov.br/home/index.jsp?arquivo=legislacao.html\#prolicenciatura $>$ Acesso em: mar. 2008.

BRASIL. Anexo III da Resolução/CD/FNDE/N 34/2005 Disponível em: $<$ http://www.fnde.gov.br/home/index.jsp?arquivo=legislacao.html\#prolicenciatura $>$ Acesso em: mar. 2008.

BRASIL. Resolução/FNDE/CD/ no 49, de 29 dezembro de 2006 Disponível em: $<$ http://www.fnde.gov.br/home/index.jsp?arquivo=legislacao.html\#prolicenciatura $>$ Acesso em: mar. 2008.

BRASIL; MEC; SEED. Referenciais de Qualidade para Educação Superior a Distância, Brasília. $\quad$ Agosto $\quad$ de $2007 \quad$ Disponível $\quad$ em $<$ http://portal.mec.gov.br/seed/index.php?option=com_content\&task=view\&id=248\&Itemid= 426> Acesso em: abr. 2008.

CORREIA, Margarita. Coaching - Tutoria, 2007. Disponível em $<$ http://www.ait.pt/index2.htm?http://209.85.207.104/search?q=cache:rf7P2sWSJioJ:www.ait $. \mathrm{pt} / \mathrm{bolsa} / \mathrm{bolseiros} /$ coaching. $\mathrm{htm}+$ houaiss + tutor $\& \mathrm{hl}=\mathrm{pt}-\mathrm{BR} \& \mathrm{ct}=\mathrm{clnk} \& \mathrm{~cd}=4 \& \mathrm{gl}=\mathrm{br}>\quad$ Acesso em: mar. 2008.

EDITAL do Processo Seletivo para Tutores do Curso de Licenciatura em Música Modalidade à Distância Disponível em: <http://caef.ufrgs.br/> Acesso em: abr 2007. EMERENCIANO, Maria do Socorro Jordão et. al. Ser Presença como Educador, Professor e Tutor. Disponível em:

$<$ http://www.abed.org.br/publique/cgi/cgilua.exe/sys/start.htm?UserActiveTemplate=4abed\&i nfoid=124\&sid=120> Acesso em: mar. 2008. 
FERREIRA, Aurélio Buarque de Holanda. Novo Dicionário da Língua Portuguesa 2. ed. Rio de Janeiro: Nova Fronteira, 1986. p. 1729

FERREIRA, Simone de Lucena et. al. Educação, Interatividade e Autoria na Cibercultura 2005. Disponível em: <http://www6.ufrgs.br/limc/escritacoletiva/pdf/edu.pdf> Acesso em: mar. 2008.

HARPER, Douglas. Online Etymology Dictionary, 2001. Disponível em: $<$ http://www.etymonline.com/index.php> Acesso em: mar. 2008.

HOUAISS. Dicionário eletrônico 2001 Não disponível Acesso em: mar. 2008.

LEAL, Regina Barros. A Importância do Tutor no Processo de Aprendizagem a Distância Revista Iberoamericana de Educación Disponível em: <http://www.rieoei.org/deloslectores/947Barros.PDF> Acesso em: mai. 2007.

MALLET, Roberto. O olho do ator. Palestra proferida em Blumenau no dia 07 de julho de 2000. Transcrição de Fernando Weffort.

MARKY, Thomas. Curso Elementar de Direito Romano, ed. Saraiva, 6 ${ }^{\mathbf{a}}$ ed., 1992 Disponível em <www.dji.com.br/romano/poderes e obrigacoes do tutor.htm> Acesso em: mar. 2008.

NUNES, Helena de Souza (org). Manual do Aluno Curso de Licenciatura em Música à Distância Programa Pró-Licenciaturas Fase II, 2007.

Musicalização de Professores: fundamentos do método empregado pelo CAEF da UFRGS junta à Rede Nacional SEB/MEC para Capacitação de Professores: livro do professor Porto Alegre: CAEF da UFRGS, 2005.

Relatório do Plano de Trabalho de 2006 Disponível em: <http://www.caef.ufrgs.br/relatorios/prolicen2006/RelatorioPTA2006_110208.pdf> Acesso em: mar. 2008.

SARMET, Maurício Miranda ; ABRAHÃO , Júlia Issy. O tutor em Educação a Distância: análise ergonômica das interfaces mediadoras Educação em Revista no.46 Belo Horizonte Dec. 2007 Disponível em: $<$ http://www.scielo.br/scielo.php?script=sci_arttext\&pid=S010246982007000200004\&lng=en\&nrm=iso> Acesso em: mar. 2008.

PROJETO do Curso Pró-Licenciatura Música da UFRGS Versão 39. Porto Alegre, Câmara de Graduação da UFRGS, 2006.

TUTOR In: WIKIPEDIA A enciclopédia Livre Disponível em:

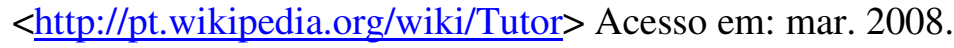

TUTOR In: WIKIPEDIA The Free Encyclopedia Disponível em:

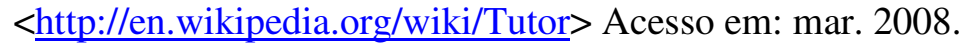

